\title{
XML Path Language
}

National Cancer Institute

\section{Source}

National Cancer Institute. XML Path Language. NCI Thesaurus. Code C47883.

XPath is a language that describes a way to locate and process items in Extensible Markup Language (XML) documents by using an addressing syntax based on a path through the document's logical structure or hierarchy. (from Computer, Telephony \& Electronics Industry Glossary) 